\title{
Sir John Thompson
}

Sir John Perronet Thompson, K.C.S.I., K.C.I.E., who died in London on the 8th August last, became a member of the Society in 1907 and had for the last two years been a Member of the Council. He was born in 1873 and had a brilliant University career, obtaining during his stay at Cambridge a scholarship at Trinity College, a first-class in the Classical Tripos, and the Presidency of the Union. In 1896 he passed into the Indian Civil Service, and he otained a high reputation in that Service as Chief Secretary to the Punjab Government, Political Secretary to the Government of India, and Chief Commissioner of Delhi. Of his services as an administrator in India, and of the political work in England which absorbed so much of his time after his retirement in 1932, it is not for this Journal to speak ; but there was another side to Sir John Thompson's interests and character, which especially concerns. members of the Royal Asiatic Society. Not only had he throughout his official service devoted himself to the study of the culture, history, and literature of India, but he had approached these subjects with a full equipment of the best form of Cambridge classical scholarship. In his work, whether official or literary, he was clear, persuasive, and meticulously accurate, and his mind was permeated by a knowledge of, and admiration for, all that was highest in European and Indian literature. The wonderful exhibition of Mogul art and antiquities held at Delhi during the Durbar of 1911 owed its success and its remarkable catalogue to his precise industry and erudition. His scholarly acquaintance with Urdu and Persian gave him access to the original sources of Muslim history in India, and if his official preoccupations had not stood in the way, it was hoped that he would have produced an attractive and authoritative account of the history and antiquities of the Delhi which he knew so well. As it is, he has left all too little of himself in print, but a reference to such papers as his memoir on the tomb of Jahangir 
in the first number of the Punjab Historical Society's Journal will indicate the high standard which would have characterized any further work he might have produced. His premature death has deprived the Society of a real scholar and of an earnest and upright supporter of all that the Society stands for.

E. D. Maclagan. 